\title{
WTEREFAEETEENOLÓGCACA
}

\section{UM ESTUDO SOBRE MÁQUINAS E EQUIPAMENTOS NO AMBIENTE COM RISCOS OCUPACIONAIS NO SETOR ALIMENTÍCIO}

\section{A STUDY ON MACHINES AND EQUIPMENT IN THE ENVIRONMENT WITH OCCUPATIONAL RISKS IN THE FOOD SECTOR}

Célia Daiane da Silva - celiadaiane@ hotmail.com
Daniela Rodolpho - danirodolpho@yahoo.com.br Faculdade de Tecnologia de Taquaritinga (FATEC) - SP - Brasil

DOI: 10.31510/infa.v15i2.431

\begin{abstract}
RESUMO
O presente trabalho tem como estudo mostrar a norma regulamentadora 12 (máquinas e equipamentos), para saber quais os riscos ocupacionais que podem-se existir no ambiente com riscos físicos, químicos, ergonômicos, biológicos e acidentes ou mecânicos. O trabalho irá mostrar como funciona os riscos ocupacionais dentro de uma empresa alimentícia adotando melhores condições de segurança para o trabalhador para obter um ambiente seguro e agradável para todos os funcionários. Para analisar os riscos que podem ocorrer no setor alimentício, foi aplicado um questionário com algumas questões abertas com alguns funcionários da área alimentícia na cidade de Monte Alto - SP. Após ser feita a análise das respostas dos funcionários, conclui-se que as empresas têm riscos ocupacionais e que precisariam de algumas mudanças para maior segurança do trabalhador, assim as empresas teriam que proporcionar aos funcionários mais palestras e treinamento para alertar os riscos que podem ocorre no ambiente de trabalho.
\end{abstract}

Palavras-chave: Máquinas e Equipamentos. Riscos Ocupacionais. Segurança

\begin{abstract}
The present study has as a study to show the regulatory norm 12 (machines and equipment), to know what occupational risks can exist in the environment with physical, chemical, ergonomic, biological and accident or mechanical risks. The work will show how occupational hazards work within a food business by adopting improved worker safety to provide a safe and enjoyable environment for all employees. To analyze the risks that may occur in the food sector, a questionnaire was applied with some open questions with some food workers in the city of Monte Alto - SP. After analyzing the employees' responses, it was concluded that companies have occupational hazards and that they would need some changes for greater worker safety, so companies would have to provide employees with more lectures and training to warn of the risks that may occur on the desktop.
\end{abstract}

Keywords: Machines and equipment. Occupational Risks. Safety 


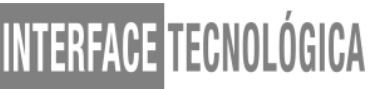

\section{INTRODUÇÃO}

"As máquinas e os equipamentos devem ser dotados de dispositivos de partida e parada e outros que se fizeram necessários para a prevenção de acidentes do trabalho, especialmente quanto ao risco de acionamento acidental (art. 184 da CLT)" (GARCIA, 2011, p. 54).

É permitida a movimentação segura de máquinas e equipamentos fora das instalações físicas da empresa para reparos, adequações, modernização tecnológica, desativação, desmonte e descarte (BRASIL, 1978).

Toda modificação para proteção de uma máquina seja geralmente pequena, o projeto todo se torna importante por envolver os setores de manutenção, operações, compras, programação e, naturalmente, o gerente de segurança e saúde (ASFAHL, 2005).

Para realizar um trabalho de gestão do risco ocupacional, é necessário entender os perigos e riscos no trabalho, assim desenvolver formas para gerenciar estas informações através de um sistema de gestão. Os processos indústrias evoluíram, pois temos equipamentos de alta produção realizando o que muitas pessoas não conseguem produzir. Entretanto, mesmo com alta tecnologia, em qualquer processo produtivo, teremos pessoas trabalhando, com isso sempre continuaremos com os riscos ocupacionais, cabe a organização junto com seus colaboradores e principalmente sua equipe de segurança do trabalho, diminuir ou eliminar estes riscos (BERKENBROCK; BASSANI, 2010).

A escolha do tema proposto deve-se à observação de vários acidentes de trabalho vem acontecendo cada vez mais no mundo, mesmo com vários investimentos possíveis para a segurança como treinamento, procedimentos e investimento. Ainda existem vários acidentes entre máquinas e equipamentos no setor alimentício, nesse sentido devemos compreender a NR-12.

Existem muitos acidentes de trabalho ocorrendo em empresas devido a máquinas e equipamentos, por isso quais técnicas e medidas de proteção que podem ser adotadas no ambiente alimentício para a saúde e segurança do trabalhador.

O objetivo geral desta proposta de trabalho é definir em referências técnicas, princípios fundamentais e medidas de proteção para garantir a saúde e a integridade física dos trabalhadores estabelece requisitos mínimos para a prevenção de acidentes e doenças do trabalho nas fases de projeto e de utilização de máquinas e equipamentos de todos os tipos, e ainda à sua fabricação, importação, comercialização, exposição e cessão a qualquer título, em 
todas as atividades econômicas, sem prejuízo da observância do disposto nas demais Normas Regulamentadoras - NR aprovadas pela Portaria No 3.214, de 8 de junho de 1978, nas normas internacionais aplicáveis (GUIA TRABALHISTA, 2011).

Os objetivos específicos são aprofundar o conhecimento sobre os riscos ocupacionais no setor alimentício em que ocorre acidentes com máquinas e equipamentos.

Foi realizado um referencial teórico sobre conceitos de acidentes de trabalho e prevenção dos riscos ocupacionais para a compreensão do assunto a ser estudado nos itens 2 e 3.

Portanto no item 4 descreve o método de pesquisa adotado para esse artigo, assim a metodologia do estudo de caso realizado na cidade de Monte Alto - SP, nas empresas Alfa e Beta (nomes fictícios), onde mostra os riscos ocupacionais que podem acontecer no ambiente de trabalho, pois adotando medidas de proteção os trabalhadores possam adquirir um ambiente seguro e agradável a todos.

\section{ACIDENTES DE TRABALHO}

Segundo COSTA (2009, p. 81), pode-se então definir acidente do trabalho como "um ataque inesperado ao corpo humano ocorrido durante o trabalho, decorrente de uma ação traumática violenta, subitânea, concentrada e de consequências identificadas", que, diferentemente da doença profissional ou do trabalho, possibilita identificar o exato momento em que ocorreu a lesão e, assim sendo, se pode estabelecer a cronologia entre lesões ocorridas sucessivamente.

Segundo a Lei 8.213/1991 conceitua Acidente do Trabalho, em seu artigo 19 da seguinte forma:

Art. 19. Acidente do trabalho é o que ocorre pelo exercício do trabalho a serviço da empresa ou pelo exercício do trabalho dos segurados referidos no inciso VII do art. 11 desta Lei, provocando lesão corporal ou perturbação funcional que cause a morte ou a perda ou redução, permanente ou temporária, da capacidade para o trabalho. (BRASIL, 1991, p. 5).

A proteção à saúde e à segurança é um direito garantido a todos os trabalhadores e trabalhadoras brasileiras, mas apesar dos esforços em neste sentido, o país registrou em 2014 mais de 704 mil acidentes de trabalho. Muitas são as dúvidas quando o assunto é acidente de trabalho, empregados e empregadores precisam ficar alerta a práticas que reduzam o número de acidentes e o que fazer caso eles ocorram (SAMPAIO, 2016). 


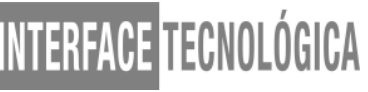

Os acidentes são resultados de interações inadequadas entre o homem, a tarefa e o seu ambiente. $\mathrm{O}$ acidente pode ser causado por um comportamento de risco do operador, pelas inadequações do posto de trabalho, produtos mal projetados ou falhas da máquina, além de fatores do meio ambiente, tais como buracos na estrada. No entanto geralmente é quando existe uma junção de fatores negativos, é que ocorrem os acidentes (IIDA, 2005).

\section{PREVENÇÃO DOS RISCOS OCUPACIONAIS EM MÁQUINAS E EQUIPAMENTOS NO SETOR ALIMENTÍCIO}

Segundo Vilela (2010), a seleção e aplicação das diferentes técnicas de segurança em máquinas requer um envolvimento e participação dos diferentes atores que participam da cadeia produtiva. Além das empresas que compram e dos trabalhadores que operam com as máquinas, nesta cadeia participam ainda os setores de fabricação e projeto, de venda, dos serviços de instalação e de manutenção.

\begin{abstract}
Art. 166. A empresa é obrigada a fornecer aos empregados, gratuitamente, equipamento de proteção individual adequado ao risco e em perfeito estado de conservação e funcionamento, sempre que as medidas de ordem geral não ofereçam completa proteção contra os riscos de acidentes e danos à saúde dos empregados. (BRASIL, 2017, p.189).
\end{abstract}

De acordo com Vilela (2010), além dos riscos mecânicos, que são mais enfocados neste trabalho, as máquinas podem representar outros riscos aos trabalhadores (ruído, calor, vibração, radiação, etc).

\subsection{Fatores de risco}

A norma regulamentadora NR-12 estabelece que as máquinas e equipamentos, trata-se do ambiente com riscos ocupacionais como físicos, químicos, biológicos, ergonômicos, acidente, cada risco ocupacional é identificado por uma cor diferenciada, o que acarreta a facilidade de realizar a sinalização, a qual contribui, portanto, para a segurança do trabalhador.

Segundo Muniz (2014), as classificações dos fatores dos ricos ocupacionais são:

- Grupo Verde 1 - Risco Físico (Agentes: Ruídos, Vibrações, Radiações ionizantes, Radiações não ionizantes, Frio, Calor, Pressões anormais e Umidade).

- Grupo Vermelho 2 - Riscos Químicos (Agentes: Poeiras, Fumos, Névoas, Neblina, Gases, Vapores e Produtos químicos em geral). 


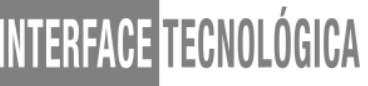

- Grupo Marrom 3 - Riscos Biológicos (Agentes: Vírus, Bactérias, Protozoários, Fungos, Parasitas e Bacilos).

- Grupo Amarelo 4 - Riscos Ergonômicos (Agentes: Esforço Físico intenso, Levantamento e transporte, Exigência de postura inadequada, Controle rígido de produtividade, Imposição de ritmos excessivos, Trabalho em turno e noturno, Jornada de trabalho prolongado, Monotonia e repetitividade e outras situações causadores de estresse físico e/ou psíquico).

- Grupo Azul 5 - Riscos de Acidentes ou Mecânicos (Agentes: Arranjo físico inadequado, Máquina e equipamento, Ferramentas inadequadas ou defeituosas, Iluminação inadequada, Eletricidade, Probabilidade de incêndio ou explosão, Armazenamento inadequado e Animais peçonhentos e outras situações de riscos que poderão contribuir para ocorrência de acidentes).

\section{METODOLOGIA DE PESQUISA}

O estudo de caso realizado nesse trabalho consistiu em uma pesquisa descritiva e exploratória.

Segundo Gil (2006), as pesquisas descritivas têm como objetivo primordial a descrição das características de determinada população ou fenômeno ou, então, o estabelecimento de relação entre variáveis. São inúmeros os estudos que podem ser classificados sob este título e uma de suas características mais significativas está na utilização de técnicas padronizadas de coleta de dados, tais como o questionário e a observação sistemática.

Já a pesquisa exploratória tem como compreender melhor o tema abordado pelo pesquisador.

O objetivo de pesquisa é os riscos ocupacionais que podem acontecer no setor alimentício.

Como estudo de caso, foi realizado uma pesquisa com 10 trabalhadores em duas empresas representativa do setor alimentício, localizada no município de Monte Alto - SP, através da aplicação com um questionário semi-estruturado. 


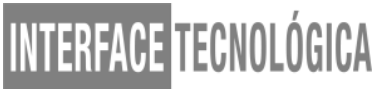

Quadro 1- Questionário aplicado aos funcionários que trabalham nas empresas

\begin{tabular}{|c|c|}
\hline 1. & Quantos anos você trabalha na empresa alimentícia? \\
\hline 2. & Qual é o cargo que exerce na empresa? \\
\hline 3. & O trabalhador tem facilidade com máquinas e equipamentos? \\
\hline 4. & Na empresa tem treinamentos de máquinas e equipamentos para os trabalhadores? \\
\hline 5. & $\begin{array}{l}\mathrm{Na} \text { empresa em que você trabalha já ocorreu algum acidente com você? Ou já } \\
\text { presenciou algum acidente com máquinas e equipamentos? }\end{array}$ \\
\hline 6. & As máquinas e equipamentos tem alguma proteção para a segurança do trabalhador? \\
\hline 7. & $\begin{array}{l}\mathrm{Na} \text { empresa que você trabalha ocorreu alguns riscos ocupacionais como: Riscos } \\
\text { Físicos, Químicos, Biológicos, Ergonômicos ou Acidentes. Se for a opção "SIM" qual } \\
\text { o agente? }\end{array}$ \\
\hline 8. & Na sua opinião o que precisaria mudar na empresa para a segurança do trabalho? \\
\hline
\end{tabular}

Fonte: AS AUTORAS (2018)

\section{ESTUDO DE CASO}

\subsection{Características das empresas}

O estudo de caso foi realizado em duas empresas nomeadas com o nome fictício Alfa e Beta, ambas localizadas no município de Monte Alto, no interior de São Paulo.

A empresa Alfa está no mercado a 22 anos e apresenta ao mercado alimentício um mix de produtos como: molhos de tomate em sachê, doces, geleias, cremes, frutas em calda, atomatados, molhos e pratos prontos, vegetais, entre outros.

A empresa Beta está ao mercado a 71 anos, mas na cidade de Monte Alto a sua unidade está fundada a 38 anos e apresenta ao mercado alimentício a produção de conservas, molhos e condimentos.

\subsection{Análise dos dados}

Após a aplicação do questionário com o total de 10 trabalhadores, 5 trabalhadores da empresa Alfa e 5 trabalhadores da empresa Beta, obteve-se um conjunto de dados das questões abordadas. 
Na empresa Alfa os 5 entrevistados têm admissão entre 2 anos a 19 anos, com os seguintes cargos:

2 Operador de máquina

1 Coordenador de produção

1 Auxiliar de produção

1 Eletricista de manutenção industrial

Os entrevistados que trabalham com máquinas não têm dificuldade com os equipamentos, pois são treinados antes de assumirem tal responsabilidade e com o tempo o trabalhador vai adquirindo prática e conhecimento com as máquinas e equipamentos.

A empresa Alfa tem treinamentos específico para cada área e durante o ano é feita palestras semanais específicas sobre qualidade, segurança e produção.

$\mathrm{Na}$ empresa Alfa, os entrevistados já presenciaram um acidente de trabalho e com alguns já ocorreu acidentes com eles mesmos, como por exemplo: um colaborador ao fazer a limpeza de um tanque com o mexedor ligado e depois de alguns minutos ela desligou-se automaticamente e machucou braço. E também tem entrevistados que nunca presenciou acidentes e nem ocorreu acidentes com eles mesmo, pois na empresa oferece reuniões mensalmente de Diálogo de Segurança que mantém os trabalhadores informados dos riscos de acidentes que pode ocorrer na empresa.

$\mathrm{Na}$ empresa Alfa as máquinas e equipamentos atendem as normas de segurança (NR 12), as máquinas têm sensores nas portas quanto abre a porta o alarme aciona e a máquina para de funcionar, enquanto estiver com o alarme a máquina não liga, tem botões de emergência em caso de parada com urgência.

Os riscos ocupacionais que ocorre na empresa Alfa é:

- $\quad$ Sim existe riscos físicos são eles: ruído, calor e vibrações.

- $\quad$ Sim existe riscos químicos são eles: gases, vapores, substância compostas.

- Não existe riscos biológicos na empresa.

- Sim existe riscos ergonômicos são eles: esforço físico intenso, levantamento e transporte manual de peso, Monotonia e repetitivo e trabalho em turno e noturno.

- Sim existe riscos de acidentes são eles: máquinas e equipamentos sem proteção, probabilidade de incêndio ou explosão, arranjo físico inadequado e outras situações de risco que poderão contribuir para a ocorrência de acidentes.

E na empresa Beta os 5 entrevistados têm admissão entre 1 ano a 17 anos, com os seguintes cargos: 


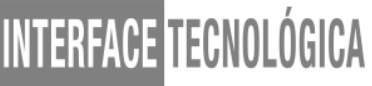

3 Operador de máquinas

1 Auxiliar de produção

1 Ajudante geral

Os entrevistados têm facilidade com máquinas e equipamentos, pois as máquinas são fáceis de operação.

$\mathrm{Na}$ empresa Beta só tem treinamentos quando as máquinas e equipamentos são novos, já a máquina antiga aprende-se a manuseá-la com um operador com mais experiência que ensina os procedimentos operacionais da máquina.

$\mathrm{Na}$ empresa Beta os entrevistados já presenciaram um acidente de trabalho e com alguns já ocorreu acidentes com eles mesmo, como por exemplo: um trabalhar teve uma queimadura no braço em um cano a vapor que não tinha a proteção adequada.

$\mathrm{Na}$ empresa Beta as máquinas novas têm como proteção portas de acrílico com sensores assim que abertas à máquina para de funcionar e tem também botão de emergência, já as máquinas antigas precisaria de algumas modificações para melhorar a segurança do trabalhador. A empresa também fornece para cada trabalhador os EPIs (Equipamento de Proteção Individual).

Os riscos ocupacionais que ocorre na empresa Beta é:

- $\quad$ Sim existe riscos físicos são eles: ruídos, calor.

- Sim existe riscos químicos são eles: poeiras, vapores.

- Não existe riscos biológicos na empresa.

- $\quad$ Sim existe riscos ergonômicos são eles: levantamento e transporte manual de peso, monotonia e repetitividade.

- $\quad$ Sim existe riscos de acidentes são eles: máquina e equipamento sem proteção.

Nas duas empresas ocorre riscos físicos, químicos, ergonômico e acidentes, mas também nas duas não ocorre o risco biológico.

Ambas as empresas precisam de melhorias para a maior segurança do trabalhador como em questão a ventilação, pois dentro das fábricas faz muito calor e também oferecer mais treinamentos para orientação os funcionários sobre os riscos que podem acontecer na empresa para ter uma maior segurança. As empresas precisariam ter uma maior atuação da segurança do trabalhador com relação a prevenção de acidentes, orientações e inspeção com o uso de EPIs e EPCs (Equipamento de Proteção Coletiva), pois muitas vezes só acontece 
acidente por causa que o funcionário não usa os equipamentos de segurança que a empresa oferece.

\section{CONSIDERAÇÕES FINAIS}

Após a aplicação do questionário nas empresas Alfa e Beta, no município de Monte Alto - SP, observou-se que os trabalhadores não têm dificuldade de manusear a máquinas e equipamentos, pois são treinados antes de exercer qualquer atividade.

$\mathrm{Na}$ empresa Alfa tem mais treinamentos para a segurança do trabalho já a empresa Beta precisaria de mais treinamentos para seus trabalhadores falando de segurança e usos que equipamento individual.

Observando os entrevistados do questionário, todas as duas empresas já aconteceram acidentes com seus funcionários ou alguns deles já presenciou um acidente com o seu colega de trabalho.

As empresas têm proteção de segurança nas máquinas e equipamentos para maior segurança do trabalhador, só na empresa Beta que algumas máquinas são antigas e não tem proteção adequada conforme a NR 12 (máquinas e equipamentos).

As empresas poderiam antes de começar o serviço fazer uma ginástica laboral para seus funcionários, principalmente em questão o risco ergonômico, pois muitos trabalhos são de monotonia e repetitivos.

\section{REFERÊNCIAS}

ASFAHL, C. R. Gestão de segurança do trabalho e saúde ocupacional. 1a. ed. São Paulo: Reichmann \& Autores Editores, 2005, p. 277.

BERKENBROCK, P. E.; BASSANI, I. A. Gestão do risco ocupacional: uma ferramenta em favor das organizações e dos colaboradores. Revista Interdisciplinar Científica Aplicada. Blumenau, 2010. Disponível em: <http://rica.unibes.com.br/index.php/rica/article/viewFile/360/318>. Acesso em: 22 ago. 2017.

BRASIL. Constituição (1978). Portaria no 3214, de 08 de junho de 1978. Aprova As Normas Regulamentadoras - NR - do Capítulo V, Título II, da Consolidação das Leis do Trabalho, Relativas A Segurança e Medicina do Trabalho. Brasília, DF, 06 jul. 1978. 
Constituição (1991). Lei no 8123, de 24 de julho de 1991. Dispõe Sobre Os Planos de Benefícios da Previdência Social e Dá Outras Providências. Brasília, DF, 24 jul. 1991, p. 5. Disponível em: <https://livrariadamasio.com.br/conteudo_complementar/pdf/Lei_8.21391.pdf>. Acesso em: 27 nov. 2018.

p.189.

Consolidação das Leis do Trabalho - CLT e normas correlatas. Brasília. 2017,

COSTA, Hertz Jacinto. Manual de Acidente do Trabalho. 3. ed. rev. e atual. Curitiba:

Juruá, 2009, p. 81.

GARCIA, G. F. B. Meio Ambiente do trabalho: Direito, Segurança e Medicina do trabalho. 3 ed. São Paulo: Método, 2011, p. 54.

GUIA TRABALHISTA. NR-12 Segurança do trabalho em máquinas e equipamentos, 011. Disponível em: <http://www.guiatrabalhista.com.br/legislacao/nr/nr12.htm>. Acesso em: 06 set. 2017.

GIL, A. C. Como elaborar projetos de pesquisa. 4.ed. p - 42. São Paulo. Editora Atlas. 2006.

IIDA, I. Ergonomia: Projeto e produção. 2.ed. São Paulo: Edgard Blucher, 2005.

MUNIZ, L. Segurança do trabalho em serviços de alimentos e bebidas, 2014, p. 1-91. Disponível em:

$<$ https://sisacad.educacao.pe.gov.br/bibliotecavirtual/bibliotecavirtual/texto/CadernodeRBSeg uranadoTrabalhoemServiodeAlimentoseBebidasRDDI.pdf >. Acesso em: 10 jul. 2018.

SAMPAIO, S. Acidentes de Trabalho: Conheça seus Direito, 2016. Disponível em: <http://trabalho.gov.br/noticias/3286-acidente-de-trabalho-conheca-seus-direitos>. Acesso em: 21 jun. 2018.

VILELA, R. A. G. Acidentes do trabalho com máquinas - identificação de riscos e prevenção. Cadernos de saúde do trabalhador, 2000, p. 1-33. Disponível em:

<http://www.cerest.piracicaba.sp.gov.br/site/images/caderno520segurancaem20maquin1.pdf> Acesso em: 11 jun. 2018. 